\title{
Tradisi Menghiasi Hewan Kurban pada Masyarakat Kenagarian Bawan
}

\author{
Edriagus Saputra \\ Pascasarjana Universitas Islam Negeri Imam Bonjol Padang \\ saputraedriagus@gmail.com
}

\begin{abstract}
Within the millennial era, academics had much discussed the science of living hadith. It even used as one of the supporting knowledge in exploring the traditions in the community. One of them is the tradition of adorning sacrificial animals in Kenagarian Bawan. It carried out before slaughtering the animals. This research explored the tradition by using ethnographic approach in the hadith living. The research found that the community had different understanding about this tradition. Some of them argued that it was a legitimate condition for completing the sacrificial worship since this tradition was an implementation of a hadith of the prophet Muhammad SAW; “... adorn your sacrificial animal because you will ride it at Shirat". It means to sacrificing the best animal, well selected and decorated, to Allah SWT. The other reason to keep this tradition was because it has done for years.
\end{abstract}

Keywords: Tradition; Adorn Sacrificial Animals; Kenagarian Bawan

\begin{abstract}
Abstrak
Dalam era milenial sekarang, para akademisi telah banyak membahas ilmu living hadis. Ilmu ini bahkan digunakan sebagai ilmu pendukung dalam mempelajari tradisi yang berkembang di tengah masyarakat. Salah satunya adalah tradisi menghiasi binatang kurban di Kenagarian Bawan. Tradisi ini dilaksanakan sebelum penyembelihan hewan kurban. Penelitian ini mempelajari tentang tradisi tersebut dengan menggunakan pendekatan etnografi dalam ilmu living hadis. Penelitian ini menemukan bahwa masyarakat memiliki pemahaman yang berbeda mengenai tradisi ini. Sebagian dari mereka menyatakan bahwa tradisi ini adalah syarat wajib untuk menyempurnakan ibadah kurban sebagaimana yang tercantum dalam hadis nabi Muhammad SAW; “...hiaslah hewan kurbanmu karena kamu akan mengendarainya di Shirat”. Hadis ini memerintahkan untuk mengurbankan binantang yang terbaik, yang terpilih dan terindah kepada Allah SWT. Alasan lainnya untuk melaksanakan tradisi ini adalah karena tradisi ini telah dilaksanakan secara turun temurun.
\end{abstract}

Kata Kunci: Tradisi; Menghiasi Hewan Kurban; Kenagarian Bawan

FOKUS : Jurnal Kajian Keislaman dan Kemasyarakatan Vol. 4, No. 1, 2019

LPPM Institut Agama Islam Negeri (IAIN) Curup - Bengkulu

Available online: http://journal.staincurup.ac.id/index.php/JF

p-ISSN 2548-334X, e-ISSN 2548-3358 


\section{PENDAHULUAN}

Masyarakat merupakan suatu kelompok dan golongan yang selalu hidup berdampingan serta berinteraksi dalam segala hal. Dalam suatu masyarakat, ada perbuatan, kegiatan, acara ataupun tradisi yang dilaksanakan secara bersama-sama dan telah menjadi suatu kegiatan yang dilaksanakan secara rutin serta disampaikan secara turun temurun hingga pada anak cucu mereka. Tradisi yang dilaksanakan oleh suatu masyarakat ada kaitannya dengan ibadah yang mereka dilakukan.

Kebiasaan ataupun tradisi masyarakat dalam melaksanakan ibadah pada suatu tempat yang ada kaitannya dengan hadis-hadis Nabi Muhammad Saw., seperti tradisi-tradisi yang hidup pada masa kenabian mengacu kepada pribadi Rasulullah Saw. sebagai utusan Allah Swt. Di dalam pelaksanaannya terdapat berbagai ajaran Islam, karena keberlanjutannya terus berjalan dan berkembang sampai sekarang ini seiring dengan kebutuhan manusia. Adanya keberlanjutan tradisi itulah sehingga umat manusia zaman sekarang bisa memahami, merekam dan melaksanakan tuntunan ajaran Agama Islam yang sesuai dengan apa yang telah dicontohkan oleh Nabi Muhammad Saw. ${ }^{1}$

Di antara tradisi yang dilakukan oleh masyarakat yang berkaitan langsung dengan ibadah yang mereka lakukan, yaitu tradisi menghiasi hewan kurban pada masyarakat Kenagarian Bawan Kecamatan Ampek Nagari Kabupaten Agam. Tradisi ini telah lama berkembang di tengah masyarakat Kenagarian Bawan dan menjadi tradisi turun menurun dalam kehidupan masyarakat, sehingga jika tidak dilaksanakan tradisi ini, maka ibadah yang mereka lakukan tidak sempurna, bahkan sampai tidak sah. Sebagaimana argumen warga setempat yang bernama Ni Eva, yaitu:

Dalam pelaksanaan penyembelihan hewan kurban tersebut, maka orang yang berkurban wajib menyediakan alat-alat untuk menghiasi hewan kurban itu, seperti kaca, sisir, parfum dan lain-lain sebagainya. Jika semua itu tidak disediakan, maka pelaksanaan penyembelihan

${ }^{1}$ M. Mansyur dkk, Metodologi Penelitian Living Qur'an dan Hadis, (Yogyakarta: Teras, 2007), hlm. 105 
hewan kurban belum bisa dilaksanakan, karena tidak sah suatu ibadah kurban tanpa dihiasi terlebih dahulu. ${ }^{2}$

Selain itu, masyarakat Kenagarian Bawan juga memiliki landasan dan dalil dalam melaksanakan prosesi menghiasi hewan kurban, sebagaimana dijelaskan oleh Imam Damril yang merupakan sebagai Imam Masjid di Kenagarian Bawan, yaitu: bahwa berkurban merupakan kewajiban bagi setiap orang muslim yang memiliki kemampuan, karena berkurban merupakan salah satu cara untuk mendekatkan diri kepada Allah Swt. dan hal itu merupakan tanda ketaatan seorang hamba kepada Allah Swt. Selain itu, hewan kurban itu akan menjadi kendaraan bagi setiap muslim yang melaksanakannya pada yaumil akhir nantinya, makanya bagi orang yang melaksanakan ibadah kurban wajib menghiasi hewan kurban terlebih dahulu sebelum hendak disembelih. Kemudian, landasan bagi masyarakat berkaitan dengan tradisi menghiasi hewan kurban ini, hal itu telah diajarkan oleh Nabi Ibrahim ketika ingin menyembelih anaknya Ismail untuk disembahkan kepada Allah Swt. Sebelum disembelih Nabi Ibrahim meminta kepada Siti Hajar untuk menghiasi Nabi Ismail, karena segala sesuatu yang akan diberikan kepada Allah harus dalam keadaan baik, bersih dan indah. ${ }^{3}$

Pendapat di atas juga dikuatkan oleh seorang Ulama Kenagarian Bawan yang bernama Tuangku Imam Panjang, ia berpendapat: Tradisi menghiasi hewan kurban merupakan kewajiban bagi setiap muslim untuk mengerjakannya dalam pelaksanaan ibadah kurban dan memberikan secara ikhlas serta hewan yang terbaik untuk disembahkan kepada Allah Swt., sebagaimana Rasulullah Saw. memerintahkan melalui sabdanya, yang artinya: ... perbaguslah hewan kurban kalian, karena dia akan menjadi kendaraan kalian untuk menitis shiratul Mustaqim (untuk menuju syurga). ${ }^{4}$

\footnotetext{
${ }^{2}$ Eva Endriani, wawancara dengan masyarakat Kenagarian Bawan, pada tanggal 18 November 2018 pukul 16. 26 WIB.

${ }^{3}$ Damril, wawancara dengan Imam Masjid Nurul Jadid Padang Sibalungking Kenagarian Bawan, pada tanggal 23 Agustus 2018 pukul 11.18 WIB.

${ }^{4}$ Tuanku Imam Panjang, wawancara dengan Ulama Kenagarian Bawan pada tanggal 27 Agustus 2018 pukul 14.45 WIB.
} 
Jadi, sebagaimana tradisi yang berkembang di Kenagarian Bawan, tulisan ini akan menelusuri lebih jauh berkenaan dengan kegiatan tradisi menghiasi hewan kurban di Kenagarian Bawan, yaitu: Bagaimanakah Sejarah dan Asal usul, transmisinya dan prosesi pelaksanaannya serta bagaimana nilai-nilai yang terkandung dalam pelaksanaan tradisi ini, sehingga dapat menciptakan suatu bentuk solidaritas yang tinggi antar masyarakat Kenagarian Bawan.

Jika dirujuk dengan kajian terdahulu, kajian ini belum ada ditemukan dalam bentuk sebuah karya ilmiah. Kemudian, melalui bantuan media online, ditemukan beberapa jurnal online yang menjelaskan tentang pelaksanaan tradisi sebelum perayaan Idul Adha/ibadah kurban, yaitu: pertama, Grebeg Gunungan yang dilaksanakan oleh masyarakat Yogyakarta sesaat menjelang Idul Adha, dalam tradisi itu dibuat tiga gunungan yang memuat berbagai macam makanan dan diarak sekeliling kampung serta dikawal oleh dua orang prajurit dengan mengendarai kuda. Arakan itu berakhir di sebuah masjid dan dilanjutkan dengan pelaksanaan doa bersama, setelah itu masyarakat yang hadir berebut untuk mengambil makanan yang terdapat dalam tiga gunungan itu yang mereka percayai dapat mendatangkan berkah. ${ }^{5}$ Kedua, tradisi Apitan yang dilaksanakan oleh masyarakat Semarang, Jawa Tengah. Tradisi ini dilaksanakan setiap tahun sesaat menjelang hari raya idul Adha dalam bentuk rasa syukur kepada Allah Swt. Atas rezeki yang telah diberikan-Nya. Pada tradisi ini, masyarakat setempat membawa hasil bumi yang mereka usahakan dan diarak sekeliling kampung yang berujung di kantor Kelurahan setempat serta menggelar doa bersama dan dilanjutkan dengan berebut hasil bumi yang telah diarak tersebut. ${ }^{6}$ Ketiga, tradisi manten sapi yang dilakukan oleh masyarakat pasuruan. Tradisi ini dilaksanakan sehari sebelum pelaksanaan hari raya idul Adha atau sebelum hewan kurban disembelih dengan tujuan untuk menghormati hewan kurban yang akan disembelih. Bentuk prosesi manten sapi ini dengan cara menghiasi sapi yang akan

\footnotetext{
${ }^{5}$ M. Anas, 3 Tradisi Unik Perayaan Idul Qurban di Indonesia (2015).Kompas.com https://travel.kompas.com.

${ }^{6}$ Heri Dwi Santoso, Apitan: Pelestarian Tradisi Agraris Lokal Masyarakat Jawa. Vol. 3, No. 2 (2013). doi: https://doi.org/10.26714/lensa.3.2.2013.11-19.
} 
disembelih dan dikalungkan bunga tujuh rupa lalu dibaluti dengan kain putih agar terlihat cantik dan tampan pada saat prosesi. Kemudian, hewan itu diarak oleh masyarakat sekitar sekeliling kampung dan warga perempuan membawa peralatan masak serta bumbu dapur untuk acara masak bersama dan yang arakan itu berakhir pada tempat pelaksanaan penyembelihan hewan kurban. ${ }^{7}$

Kajian ini merupakan kajian living hadis Field Research (kajian lapangan) dalam menggunakan pendekatan Etnografi, karena tradisi menghiasi hewan kurban merupakan suatu tradisi/kebudayaan yang berkembang di tengah masyarakat dan dilaksanakan secara kontinu pada setiap tahunnya serta berkaitan langsung dengan hadis Rasulullah Saw. dalam pelaksanaan ibadah kurban. Penelitian dengan menggunakan pendekatan Etnografi ini terpusat pada sebuah kelompok, aliran maupun komunitas yang terdapat di dalam suatu masyarakat yang memiliki kebudayaan yang sama. Boleh jadi, kelompok yang kecil maupun kelompok yang besar dan banyak melibatkan orang dalam berinteraksi untuk melaksanakannya. ${ }^{8}$ Maka kajian ini terfokus pada masyarakat Kenagarian Bawan Kecamatan Ampek Nagari Kabupaten Agam.

\section{PEMBAHASAN}

\section{Potret Wilayah Kenagarian Bawan}

Kenagarian Bawan merupakan sebuah Nagari pada Kecamatan Ampek Nagari yang berada di Kabupaten Agam Provinsi Sumatera Barat. Kenagarian Bawan berdiri pada tahun 2005, yaitu Nagari Mekaran dari Nagari Tigo Koto, Batu Kambing. Pada tanggal 25 Februari 2005, Nagari Tigo Koto mekar menjadi 3 Nagari, yaitu Nagari Sitanang, Nagari Bawan dan Nagari Batu Kambing sebagai Nagari Induk. Semua Nagari tersebut terletak pada Kecamatan Ampek Nagari, yaitu Nagari Sitanang, Nagari Batu Kambing, Nagari Sitalang, dan Nagari Bawan. Nagari Bawan

\footnotetext{
${ }^{7}$ Nguling, Tradisi Manten Sapi untuk Syiar Islam (2016).Warta Bromo https://www.wartabromo.com.

${ }^{8}$ Saifuddin Zuhri dan Subkhani Kusuma Dewi, Living Hadis (Praktik, Resepsi, Teks dan Transmisi), ( Yogyakarta: Q Media, 2018), hlm. 6-7.
} 
memiliki luas wlayah 56.400 Ha yang dihuni oleh 14.569 orang penduduk.

Kenagarian Bawan merupakan Nagari yang memiliki daerah yang sangat luas dibandingkan dengan Nagari-nagari yang berada di Kecamatan Ampek Nagari. Nagari Bawan memiliki Lima (5) Jorong, yaitu Jorong Anak Aie Kasiang, Jorong Lubuk Alung, Jorong Puduang, Jorong Malabur dan Jorong Pasar Bawan yang sekaligus sebagai pusat pemerintahan Kenagarian Bawan.

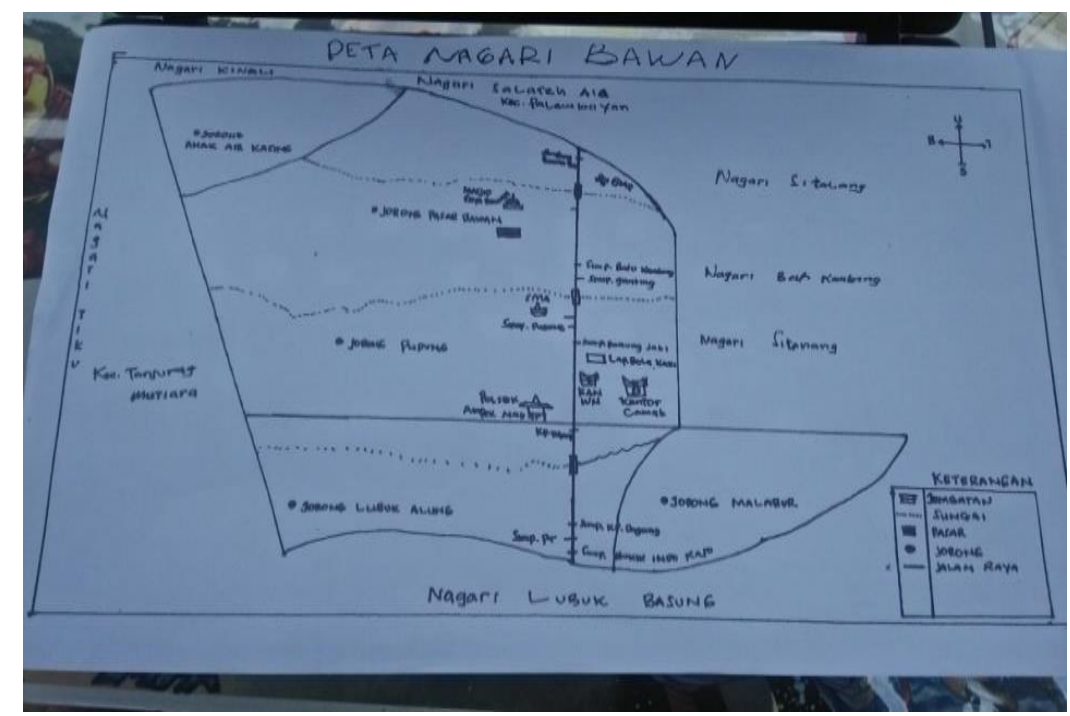

Gambar 1: Peta Kenagarian Bawan

Keterangan:

Sebelah Utara : Nagari Salareh Aie Barat

Sebelah Selatan : Nagari Lubuk Basung

Sebelah Barat : Nagari Tiku Limo Jorong

Sebelah Timur : Nagari Batu Kambing

Kenagarian Bawan terletak pada pusat pemerintahan Kecamatan Ampek Nagari dengan jarak 20 meter. Sedangkan suhu udara pada Kenagarian Bawan pada siang hari, yaitu $29^{\circ}$ Celcius dan pada malam harinya dengan suhu udara, yaitu $24^{0}$ Celcius. 
Dalam sebuah Nagari yang terletak pada jalan lintas Padang-Pasaman pasti memiliki sarana prasarana yang mendukung demi kemajuan dan perkembangan daerahnya. Di antara rincian sarana prasarana tersebut, yaitu: pertama, Sarana Kesehatan terdiri dari 4 unit, yaitu 1 Puskesmas, 1 Poskesdes, 30 Posyandu dan 3 Polindes. Kedua, Sarana Pendidikan, yaitu 19 Paud dan TK, 23 SD/MI, 3 SLTP, 1 MTs, 1 SMA, 1 SMK, 1 MA dan 1 Perguruan Tinggi. Ketiga, Sarana Tempat Ibadah, yaitu 15 Unit Masjid dan 45 Unit Mushalla. Keempat, Sarana Tempat Umum, yaitu 1 Pasar Nagari dan 1 Balai Pertemuan. ${ }^{9}$

Masyarakat Kenagarian Bawan memiliki sumber penghasilan mayoritas pada bidang pertanian, seperti Kebun Sawit, Kelapa, Jagung, Pisang dan Coklat, dan ada pula yang memiliki penghasilan yang lain, seperti Buruh, Nelayan, Pedagang, PNS, TNI, dan POLRI. ${ }^{10}$

Kenagarian Bawan merupakan Nagari yang memiliki mayoritas penduduknya beragama Islam, walaupun ada sekitar 1,5\% yang beragama non muslim, namun bukan penduduk asli dari Nagari Bawan, tetapi pekerja yang bekerja di PT AMP Plation (Perusahaan Sawit terbesar di Kabupaten Agam) yang telah lama menetap serta telah tercatat sebagai penduduk Kenagarian Bawan.

Masyarakat Kenagarian Bawan memiliki 15 Masjid dan 45 Mushalla/Surau. Setiap Pekannya, Masjid/Mushalla/Surau yang berada di Kenagarian Bawan memiliki wirid Mingguan, seperti Kajian Mingguan bersama ustad-ustad yang diundang oleh pengurus Masjid/Mushalla/Surau, Wirid Yasinan yang dipandu oleh para ulama yang berada pada setiap kampung dan Wirid Bulanan (Kajian Kuno) dengan mengundang Tuangku yang berasal dari luar Kenagarian Bawan. Masyarakat Kenagarian Bawan mayoritas berasal dari Pariaman dan telah lama menetap di Kenagarian Bawan, sehingga dari tradisi (kebiasaan), kebudayaan dan tata cara ibadah sama dengan pelaksanaan orang

${ }^{9}$ Data Dokumentasi Kantor Wali Nagari Bawan Kecamatan Ampek Nagari Kabupaten Agam.

${ }^{10}$ Data Dokumentasi. 
Pariaman, seperti baralek yang memakai uang hilang, uang japuik, uang selo dan tradisi-tradisi lainnya. ${ }^{11}$

Masyarakat Kenagarian Bawan merupakan penganut aliran thariqat syatariyah yang berkembang pada daerah Ulakan, Pariaman. Thariqat ini dibawa dan dikembangkan oleh Syaikh Burhanuddin yang berguru langsung kepada Syaikh Abdurrauf Singkil, Aceh. Segala hal yang telah diajarkan, dikembangkan dan diamalkan oleh Syaikh Burhanuddin, maka akan dijaga dengan sebaik mungkin oleh para pengikutnya, baik melalui pengajaran melalui Pondok Pesantren yang berada di Pariaman, para Tuangku dengan cara menyampaikannya melalui wirid mingguan atau wirid bulanan (Kajian Kuno) dan masyarakat secara umumnya dengan cara melaksanakan segala bentuk kebiasaan/tradisi yang telah diajarkan oleh para Tuangku maupun nenek moyangnya terdahulu.

\section{Sejarah dan Asal Usul Tradisi Menghiasi Hewan Kurban}

Setiap kegiatan maupun tradisi yang dilaksanakan oleh setiap masyarakat, mayoritas memiliki asal-usul atau sejarah awalnya, sehingga dilaksanakan oleh masyarakat setempat dan begitu juga dengan tradisi menghiasi hewan kurban.

Menurut Tuangku Kaidir, sejarah dan asal usul tradisi menghiasi hewan kurban, berawal dari mimpi yang datang kepada Nabi Ibrahim as. untuk menyuruh menyembelih Nabi Ismail as. dan mimpi itu datang sampai tiga kali, sehingga Nabi Ibrahim as. meyakini merupakan sebuah perintah (wahyu) dari Allah Swt. yang wajib dilaksanakan. Setelah berdisikusi dan meminta pendapat dari Nabi Ismail as. dan Siti Hajar, maka mereka ridho dan ikhlas melaksanakan perintah dari Allah Swt.

Selanjutnya, pada esok harinya Nabi Ibrahim as. dan Siti Hajar mempersiapkan upacara pengorbanan Nabi Ismail as. yang akan diberikan kepada Allah Swt. Sebelum Nabi Ismail as. mengikuti upacara penyembelihan yang dilakukan oleh ayahnya sendiri, maka Siti Hajar mempersiapkan prosesi untuk penyembelihan Nabi Ismail as., seperti :

${ }^{11}$ Arif Eka Putra, hasil wawancara dengan Staff Kesejahteraan Nagari Bawan pada tanggal 24 Agustus 2018. 
Nabi Ismail dimandikan, dihiasi dan dipakaikan pakaian yang bagus, dengan tujuan Nabi Ismail as. akan disembahkan kepada Allah Swt., karena segala sesuatu yang diberikan dan disembahkan pada Allah, maka harus yang baik dan bagus. Setelah dibersihkan dan hiasi Nabi Ismail as., maka Nabi Ibrahim as. membawa Nabi Ismail as. ke tempat penyembelihan. Pada saat Nabi Ibrahim as. menyembelih leher dari Nabi Ismail as., maka Allah memerintahkan kepada Malaikat untuk menggantinya dengan seekor kibas, ketika itu bergantilah Nabi Ismail as. dengan seekor kibas dan yang disembelih itu adalah leher seekor kibas dan bukan lehernya Nabi Ismail as. ${ }^{12}$

Berawal dari sejarah itu, masyarakat Kenagarian Bawan melakukan prosesi menghiasi hewan kurban pada setiap tahunnya yang mereka dapati melalui pengajaran bersama para tuangku atau pengajian yang mereka lakukan disurau-surau, mushalla atau di Masjid. ${ }^{13}$

Sejarah itu juga di-ta'kid-kan oleh tuangku oleh Sidi Ali Basar yang berada di Kampung Padang Dama Nagari Bawan. Menurut tuangku Sidi Ali Basar, bahwa tradisi menghiasi hewan kurban yang berkembang di Kenagarian Bawan merupakan sebuah tradisi yang dibawa oleh para ulama atau tuangku yang belajar dan mengaji di surau-surau Pariaman serta silsilahnya langsung kepada Syaikh Burhanuddin sebagai ulama yang pertama kali menyebarkan agama Islam di daerah Minangkabau, sebagaimana dijelaskannya dalam bentuk ranji atau silsilah berkembangnya tradisi menghiasi hewan kurban di Kenagarian Bawan, yaitu: ${ }^{14}$

\footnotetext{
${ }^{12}$ Tuangku Kaidir, wawancara dengan ulama Kenagarian Bawan pada tanggal 02 Oktober 2018 pukul 05.45 WIB

13 Tuangku Kaidir.

${ }^{14}$ Tuangku Sidi Ali Basar, wawancara dengan ulama Kenagarian Bawan pada tanggal 29 Desember 2018 pukul 18.20 WIB.
} 


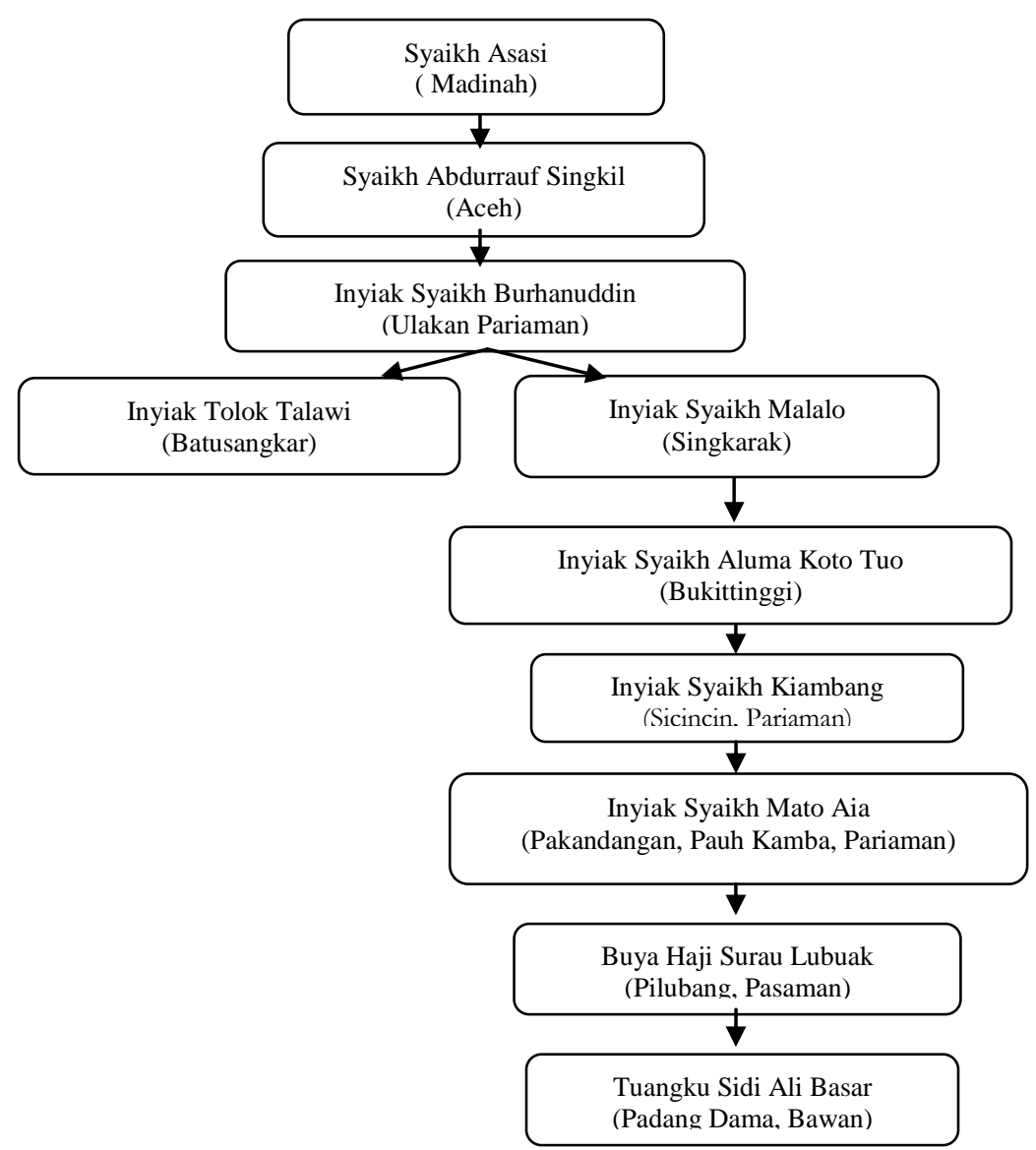

Gambar 2 : Skema Transmisi Tradisi ${ }^{15}$

Prosesi menghiasi hewan kurban merupakan salah satu bentuk tradisi masyarakat Kenagarian Bawan yang mayoritas berasal dari Pariaman untuk memberikan sesuatu yang terbaik kepada Allah Swt. Selain dalam bentuk mencari hewan-hewan yang terbaik, hewan tersebut juga dinyatakan telah lulus oleh kementerian Kesehatan setempat, baik dari kecacatan fisik maupun terhindar dari segala penyakit, maka hewan itu juga dihiasi sebagaimana manusia biasa berhias, yaitu menggunakan bedak, parfum, sisir dan sebagainya. Setelah hewan itu dihiasi, maka

\footnotetext{
${ }^{15}$ Tuangku Sidi Ali Basar.
} 
hewan kurban itu diberi makan, seperti Nasi Kuning (Silamak), Ketan Hitam (Siawu), Pinyaram dan sebagainya. ${ }^{16}$

Prosesi menghiasi hewan kurban yang dilakukan oleh masyarakat Kenagarian Bawan masih berlanjut sampai sekarang pada setiap tahunnya dan masih terjaga dengan baik serta selalu dikerjakan oleh masyarakat setempat, karena selain dari penyempurna ibadah kurban yang dilakukan masyarakat juga sebagai tradisi atau kebiasaan yang dilakukan secara turun temurun dari nenek moyang masyarakat Kenagarian Bawan dahulunya.

\section{Prosesi Pelaksanaan Tradisi Menghiasi Hewan Kurban}

Living hadis adalah suatu perilaku atau kebiasaan yang berkembang di tengah-tengah masyarakat yang telah mentradisi baik dari segi bentuk ritual, tingkah laku, maupun praktik yang hidup di masyarakat yang memiliki landasan atau dalil dengan hadis Nabi Muhammad Saw. Setelah dikonfirmasikan kepada Ulama atau Tuanku masyarakat Kenagarian Bawan berkaitan dengan tradisi menghiasi hewan kurban, maka mereka berlandaskan kepada sebuah hadis, yaitu:

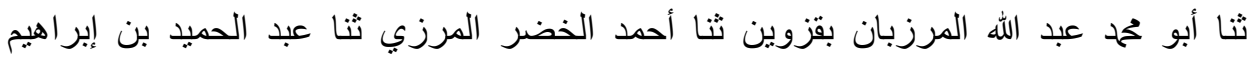

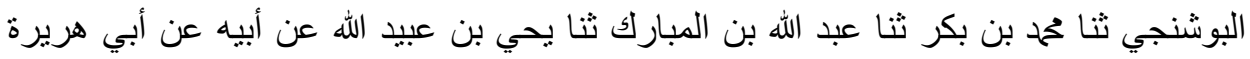

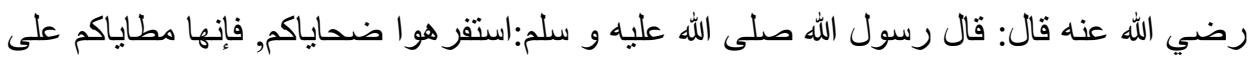

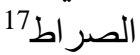

"Hadis dari Abu Muhammad Abdullah al-Marzuban biqazwin, Ahmad alQadhri al-Marzi menceritakan kepada kami, Abdul Hamid bin Ibrahim al-Busyinjiy menceritakan kepada kami, dari Muhammad bin bakr, dari Abdullah bin Mubarak dari Yahya bin Ubaidillah dari Ayahnya dari Abi Hurairah RA. Berkata, Rasulullah Saw. bersabda: Perbaguslah Hewan

${ }^{16}$ Tuangku Kaidir.

${ }^{17}$ Setelah dicari hadis tersebut melalui bantuan media Hadis Digital Lidwa, maka hadis itu tidak terdapat pada kitab Kutubus Sittah (kitab sembilan hadis). Setelah dicek melalui bantuan internet, maka hadis itu terdapat dalam Musnad Firdaus, kitab alTadwin Fii Akhbari Qazwiin hadis yang ke-1134 yang dikarang oleh Abdul Karim AlRafi'i Asy Syafi'i dan Kitab Adh-Dhoifah dengan kualitas hadis dhaif. 
Kurban kalian, karena dia akan menjadi tunggangan kalian melewati shirath".

Hadis di atas merupakan landasan utama bagi masyarakat Nagari Bawan dan para ulama dalam rangka untuk menjaga dan memelihara kebiasaan atau tradisi yang mereka lakukan sejak dahulunya. Melalui hadis tersebut, sehingga dapat dijadikan bahan penelitian tradisi yang dilaksanakan masyarakat Kenagarian Bawan dalam prosesi Menghiasi Hewan Kurban. Dalam penelitian Studi Living Hadis tidak memandang, mengkaji dan tidak menitikfokuskan kepada Keshahihan sanad dan matan suatu hadis yang dipedomani oleh masyarakat, namun praktek atau tradisi yang dilakukan oleh masyarakat memiliki landasannya dengan hadis Rasulullah Saw. Ibadah kurban dilaksanakan oleh setiap umat muslim pada hari raya Idul Adha setelah melaksanakan shalat Idul Adha atau pada hari Tasyri'. Pelaksanaan ibadah kurban pada umumnya dilakukan oleh masyarakat muslim, yaitu membawa hewan kurban ke tempat penyembelihan, disembelih dan dibagikan oleh pihak panitia kurban kepada masyarakat yang membutuhkannya. Berbeda dengan di Kenagarian Bawan, bahwa masyarakat melaksanakan ibadah kurban bukan seperti masyarakat muslim pada umumnya, tetapi masyarakat melaksanakan tradisi menghiasi hewan kurban. Ketika hendak melaksanakan ibadah kurban, maka orang yang berkurban telah menyediakan segala perlengkapan dan alat-alat untuk melaksanakan tradisi menghiasi hewan kurban, yaitu:

1. Alat-alat hias adalah alat-alat yang digunakan oleh manusia untuk menghiasi anggota tubuhnya. Di antara alat-alat yang digunakan untuk menghiasi hewan kurban serta kegunaannya, ${ }^{18}$ yaitu :

a. Bedak, yaitu alat yang digunakan untuk membedakan hewan kurban, sebagaimana manusia dihiasi. Bedak yang digunakan untuk menghiasi hewan boleh dalam bentuk dan merek bedak apapun. Tujuan hewan tersebut diberi bedak, yaitu agar hewan yang hendak disembelih nanti diakhirat bisa lebih indah dan bagus, karena hewan

\footnotetext{
${ }^{18}$ Tuangku Imam Panjang.
} 
itu akan menjadi kendaraan bagi orang yang berkurban di akhirat, sehingga hewan tersebut diberi bedak;

b. Sisir, yaitu alat yang digunakan untuk menghiasi atau menyisir rambut kepala hewan kurban. Karena sisir merupakan salah satu alat yang digunakan oleh manusia untuk menghiasi dirinya, sehingga terlihat bagus dan indah;

c. Cermin, yaitu alat yang telah disediakan oleh orang yang berkurban dengan tujuan untuk mencerminkan hewan kurban;

d. Parfum, yaitu salah satu syarat dalam menghiasi hewan kurban yang digunakan untuk diberikan kepada hewan yang hendak disembelih;

e. Lipstik, yaitu salah satu alat hias yang digunakan oleh wanita untuk menghiasi dirinya. Alat ini digunakan hanya khusus bagi yang berkurban adalah seorang perempuan;

f. Kain kafan, yaitu kain putih yang digunakan untuk membungkus jenazah. Kain kafan juga salah satu syarat dalam tradisi Menghiasi hewan kurban. Tujuan kain kafan, yaitu untuk diselimutkan kepada hewan kurban sebelum disembelih dan untuk membungkus kuku hewan setelah disembelih dan dikuburkan;

g. Kain sarung/kain panjang, yaitu kain sarung atau kain panjang merupakan salah satu syarat dalam rangka menghiasi hewan kurban yang disediakan oleh orang yang berkurban. Tujuan utama disediakannya kain itu, sebagai bahan sedekah yang akan diberikan kepada ulama menyembelih hewan. Setiap kain yang disediakan berdasarkan jenis kelamin orang yang berkurban, jika yang berkurban seorang laki-laki, maka ia menyediakan kain sarung dan jika yang berkurban adalah seorang perempuan, maka ia menyediakan kain panjang;

h. Payung, yaitu syarat lain dalam rangka untuk pelaksanaan tradisi menghiasi hewan kurban. Syarat ini harus disediakan oleh orang yang melaksanakan kurban. Kegunaan payung, yaitu untuk memayungkan orang yang melakukan penyembelihan hewan kurban. Setelah payung itu digunakan pada pelaksanaan tradisi 
menghiasi hewan kurban, maka payung tersebut disedekahkan kepada orang yang menyembelih hewan kurban; ${ }^{19}$

i. Carano, yaitu syarat lain dari tradisi menghiasi hewan kurban. Carano ini berisikan, sirih, pinang, gambia, sadah dan semua barang yang terdapat di dalam carano yang biasa digunakan oleh masyarakat Minang dalam menyambut tamu kehormatan. Menurut Beny Candra, S. Sn, dia adalah seorang guru seni lulusan ISI (Institut Seni Indonesia) Padangpanjang, ia mengatakan, bahwa carano digunakan oleh masyarakat Minang Kabau dalam rangka menyambut kedatangan seorang tamu mulia atau tamu kehormatan. $^{20}$ Selain dari alat-alat sirih yang terdapat didalam carano, masyarakat yang berkurban juga meletakkan uang (yang tidak dianggarkan uangnya atau seikhlasnya). Kegunaan dari uang tersebut, yaitu sebagai sedekah kepada orang yang melakukan penyembelihan terhadap hewan kurban.

2. Makanan adalah sesuatu yang disediakan oleh orang yang berkurban untuk diberikan kepada hewan kurban tersebut sebelum disembelih, diantara makanan yang disediakan, yaitu:

a. Nasi Kuning (Silamak), yaitu Nasi ketan yang dimasak dan dikasih atau dicampur dengan kunyit, sehingga ketan yang telah dimasak itu berwarna kuning. Nasi kuning (Silamak) kegunaannya untuk diberikan dan disuapkan kepada hewan yang hendak disembelih;

b. Nasi Hitam (Siawu), yaitu nasi ketan yang dimasak dan dicampuri dengan gula tebu (saka), sehingga nasi ketan tersebut berubah menjadi warna hitam. Nasi Hitam (Puluik Hitam) ini diberikan dan disuapkan kepada hewan yang hendak disembelih tersebut;

c. Pinyaram, yaitu sebuah makanan yang terbuat dari tepung, gula, garam dan lain-lain. Pinyaram ini diberikan dan disuapkan kepada hewan kurban. Pinyaram yang memiliki rasa manis dan asin merupakan pengganti dari air teh bagi hewan kurban, yang

\footnotetext{
19 Tuangku Imam Panjang.

${ }^{20}$ Beny Candra, wawancara dengan Guru Seni SMPIT Al Hijrah pada tanggal 08 September 2018 pada pukul 08.35 WIB.
} 
nantinya akan didapatkan oleh orang yang berkurban di akhirat kelak $;^{21}$

d. Beras Ketan yang direndang (Beras Puluik yang dirandang). Beras ketan ini sebagai pelengkap dari segi makanan yang hendak diberikan kepada hewan kurban. ${ }^{22}$

Jadi, bentuk alat dan bahan serta makanan yang disediakan oleh orang yang berkurban, semuanya akan diberikan kepada hewan yang hendak disembelih, dengan tujuan agar hewan itu merasa senang dan tidak merasa ketakutan akan disembelih. Selain itu, Nabi Muhammad Saw. juga memerintahkan kepada orang yang hendak berkurban dan penyembelih hewan kurban agar menyenang hewan serta tidak membuat hewan itu merasa ketakutan atau menzaliminya, sehingga akan berefek kepada pelaksanaan ibadah kurban maupun daging yang dihasilkannya.

Menurut Tuangku Imam Panjang, menurut Tuanku Sidi Ali Basar, bahwa menghiasi hewan kurban itu adalah: Menghiasi hewan kurban merupakan tradisi orang tua dahaulu yang telah turun temurun sampai kepada zaman sekarang. Orang dahulu yang berguru kepada Syaikh Burhannuddin di Ulakan Padang Pariaman meyakini bahwa hewan kurbannya tersebut akan menjadi kendaraan mereka di hari kiamat nantinya dan hewan itu merupakan kendaraan untuk menuju ke surga. Dengan hal tersebut masyarakat Kenagarian Bawan melaksanakan tradisi menghiasi hewan kurban. Setelah hewan tersebut dihiasi, maka hewan tersebut juga dikasih makanan yang telah disediakan oleh orang yang berkurban. ${ }^{23}$

Begitu juga menurut bapak Imwarizal, S. Pd, MM, ia adalah seorang kepala SMPN 1 Kenagarian Bawan sekaligus sebagai ketua Masjid Raya Babussalam Pasar Bawan, menurutnya tradisi menghiasi hewan kurban adalah: Menghiasi hewan kurban tersebut merupakan suatu keharusan bagi orang yang berkurban, karena hal tersebut disampaikan oleh guru-

\footnotetext{
${ }^{21}$ Imwarizal. wawancara dengan orang yang berkurban sekaligus Ketua Masjid Raya Pasar Bawan pada tanggal 22 Agustus 2018 pukul 10.37 WIB.

${ }^{22}$ Tuanku Imam Panjang.

${ }^{23}$ Tuanku Sidi Ali Basar.
} 
guru pengajian di Masjid atau di Mushalla, sehingga jika tidak dilaksanakan hal tersebut, maka ibadah yang dilaksanakan kurang sempurna, karena tidak mencukupi syarat-syaratnya. Dan hal ini bisa pula jadi bahan gunjingan bagi masyarakat seperti "sianu itu nggak sah kurbannya, karena syarat-syaratnya tidak lengkap", demi mencari kesempurnaan dalam ibadah dan menghindari diri dari gunjingan, maka diharuskan bagi orang yang berkurban untuk mempersiapkan hal-hal tersebut. Tak mungkin bagi orang yang berkurban tidak bisa menyediakan alat-alat tersebut, sedangkan hewan kurban yang harganya puluhan juta bisa mereka beli. ${ }^{24}$

Masyarakat Bawan yang mayoritas berasal dari Padang Pariaman yang beraliran keagamaan Thariqat Syatariyah dan bergurukan sampai pada syaikh Burhannuddin dan mengajarkan tentang tata cara pelaksanaan ibadah kurban secara turun temurun sampai pada anak cucunya saat sekarang ini. Maka tradisi menghiasi hewan kurban telah menjadi sebuah kewajiban bagi masyarakat dalam melaksanakan ibadah kurban. Sehingga, jika hal tersebut tidak dilaksanakan bagi suatu masyarakat di Kenagarian bawan, maka masyarakat di Kenagarian Bawan menganggap ibadahnya kurang sempurna, bahkan sampai tidak sah. Selain itu, jika suatu masyarakat tidak melaksanakan tradisi menghiasi hewan kurban, maka ia menjadi bahan gunjingan bagi masyarakat lainnya, karena ibadah kurban yang dilaksanakan tidak sah atau tidak mencukupi syarat dan tata cara pelaksanaan ibadah kurban.

Setelah semua alat dan bahan untuk pelaksanaan tradisi menghiasi hewan kurban dan telah dinyatakan lengkap oleh ulama setempat, maka dilanjutkan dengan pelaksanaan prosesi tradisi menghiasi hewan kurban, yaitu: pertama, Menghiasi Hewan Kurban, bagi masyarakat Kenagarian Bawan merupakan sesuatu prosesi yang sangat penting dalam pelaksanaan ibadah kurban, karena tanpa pelaksanaan menghiasi hewan kurban, maka ibadah kurban yang dilaksanakan tidak sempurna, bahkan sampai dinilai sebagai orang yang kikir terhadap dirinya sendiri. Tradisi

\footnotetext{
${ }^{24}$ Imwarizal.
} 
menghiasi hewan kurban ini telah menjadi turun temurun bagi masyarakat Kenagarian Bawan sampai pada anak cucu mereka.

Setelah perlengkapan dan bahan untuk menghiasi hewan kurban telah sempurna dan lengkap, maka semuanya itu akan dibawa ke masjid/mushalla atau tempat pelaksanaan penyembelihan hewan kurban. Namun, sebelum tradisi itu dilaksanakan, maka orang yang berkurban harus mengambil air wudhu' terlebih dahulu, sebagaimana dikatakan oleh bapak Zakirman, yaitu: Sebelum melaksanakan prosesi menghiasi hewan kurban, maka orang yang berkurban tersebut harus mengambil air wudhu', agar orang yang berkurban suci dan bersih serta ibadah tersebut diterima oleh Allah Swt. ${ }^{25}$

Setelah itu, maka orang berkurban melaksanakan prosesi menghiasi hewan kurban dengan diawali memberikan hewan itu bedak pipa kepada pipi hewan itu, kemudian dilanjutkan dengan memberinya lipstik (jika yang berkurban adalah perempuan), menyisir rambut/bulu diatas kepalanya serta dicerminkan dan dikasih parfum. Setelah selesai hewan tersebut dihiasi, maka hewan tersebut dipayungkan dan diberikan makanan yang telah disediakan, seperti Nasi Kuning, Pinyaram, dan Nasi Ketan Hitam. Kemudian hewan itu diselimutkan dengan kain kafan serta menghadapkannya ke kiblat dan disembelih.

Menurut Tuangku Sidi Ali Basar, bahwa prosesi penyembelihan adalah penyembelihan dilaksanakan oleh ulama yang telah dipercaya oleh masyarakat dan sebelum ia menyembelih hewan tersebut, ia membaca takbir 3 kali, membaca shalawat kepada Nabi Muhammad SAW. dan membaca niat menyembelih, yaitu

$$
\text { نويت أضحيا لله تعالى } 26
$$

Setelah hewan tersebut disembelih dengan menggunakan pisau atau alat untuk menyembelih yang tajam oleh ulama yang dipercayakan oleh masyarakat setempat, maka hewan tersebut didiamkan sejenak sampai hewan tersebut sempurna matinya. Kedua, Shalat Sunnat, setelah

25Zakirman, wawancara dengan tokoh masyarakat pada tanggal 27 Agustus 2018 pukul 16.30 WIB.

${ }^{26}$ Tuangku Sidi Ali Basar. 
melaksanakan tradisi menghiasi hewan kurban dan ulama setempat menyembelih hewan itu serta mendiamkannya sampai hewannya tidak bernyawa lagi, maka selagi menunggu hewan itu sempurna matinya, ulama mencari tempat dekat dengan hewan kurban yang telah disembelih itu dan melaksanakan shalat sunnat dua rakaat. Shalat ini hukumnya sunnah dilaksanakan, sebagaimana dijelaskan oleh Tuangku Imam Panjang, adalah : Hukum melaksanakan shalat itu adalah sunnah dengan tujuan untuk menyempurnakan amal ibadah kurban yang dilaksanakan. ${ }^{27}$

Shalat sunnat ini tidak ada dalil yang menjelaskannya, namun hal itu dilaksanakan karena telah menjadi turun temurun oleh masyarakat setempat dengan tujuan smenyempurnakan amal ibadah yang dilaksanakan. Dan mereka berasumsi, bahwa shalat itu hukumnya sunnah, maka boleh saja dilaksanakan dan begitulah guru-guru mereka terdahulu yang mengajarkan. Namun, shalat sunnat ini tidak seluruh ulama setempat melaksanakannya, karena hukumnya sunnah, maka boleh dilaksanakan dan boleh tidak. Ketiga, Membacakan Do'a, setelah melaksanakan shalat sunnah oleh ulama, maka ulama itu melanjutkan dengan membaca doa.

Setelah itu dilanjutkan dengan menguliti hewan kurban yang dilakukan oleh panitia dan orang yang telah dipercayakan oleh pihak yang berkurban. Kemudian, orang yang berkurban menyerahkan uang sedekah yang terdapat di dalam Carano kepada ulama yang menyembelih hewan kurban beserta dengan kain sarung/kain panjang yang telah disedikan oleh orang yang berkurban. Keempat, Menjamu, setelah melaksanakan semua prosesi tadisi menghiasi hewan kurban dari mempersiapkan alat-alat dan perlengkapan yang diperlukan sampai pada pembacaan doa oleh ulama yang menyembelih hewan kurban. Prosesi terakhir yang dilakukan oleh orang yang melaksanakan ibadah kurban, yaitu menjamu masyarakat setempat. Maksud dari menjamu ini, yaitu memanggil masyarakat atau warga sekitar kampung untuk datang ke rumah orang yang berkurban dengan tujuan untuk ikut serta berdoa bersama yang nantinya akan dipimpin oleh Tuanku dalam membaca doa kurbannya. Setelah itu, orang yang berkurban menjamu tamu yang datang dengan menyediakan

\footnotetext{
${ }^{27}$ Tuangku Imam Panjang.
} 
makanan dan pencuci mulut (Parabuangan). Hal itu dibenarkan oleh Tuangku Rusli Labai Basa, yaitu: Setelah masyarakat melaksanakan ibadah kurban dan menjalani seluruh prosesinya, maka tahap akhir yang dilakukan oleh orang yang berkurban, yaitu mandoa (menjamu). Orang yang berkurban memasak daging kurban yang didapatinya, setelah itu memanggil (maimbau) Alim Ulama, Imam Khatik, Tokoh Masyarakat, karib kerabat dan masyarakat sekitar untuk datang ke rumah orang yang berkurban untuk melaksanakan doa kurban (badoa basamo dalam rangka alah siap melaksanakan ibadah kurban). Hal tersebut terus dilaksanakan oleh setiap masyarakat setelah melaksanakan ibadah kurban. Tujuan dalam rangka berdoa dan menjamu, yaitu: Pertama, bentuk rasa syukur kepada Allah Swt. karena telah diberikan nikmat dan rezeki kepada orang yang berkurban, sehingga dapat melaksanakan ibadah kurban. Kedua, berdoa bersama salah satu cara yang dilakukan oleh orang yang berkurban dalam mengungkapkan rasa syukur kepada Allah Swt. Karena dengan melaksanakan berdoa bersama, doa itu cepat diijabah oleh Allah Swt., sebagaimana hadis Nabi Saw. bersabda وجمعة رحمة.... (berjama'ah itu adalah Rahmat). Ketiga, bersedekah, dengan menjamu orang yang datang ke rumah orang yang berkurban, berarti orang yang melaksanakan ibadah kurban juga telah melaksanakan sedekah, karena bersedekah itu bukan hanya saja dengan uang, tetapi juga bisa dengan menggunakan makanan dan menjamu mereka juga termasuk sedekah. Keempat, Menyambung Tali Silaturrahim, dengan mengundang Karib Kerabat, Alim Ulama, Imam Khatik dan Masyarakat sekitar, melaksanakan doa bersama dan menjamu mereka yang datang merupakan salah satu cara untuk menyambung tali silaturrahim antara orang yang berkurban dengan orang yang datang (warga sekitar). ${ }^{28}$

\footnotetext{
${ }^{28}$ Tuanku Rusli Labai Basa, wawancara dengan ulama Batang Dareh Jorong Lubuk Alung Kenagarian Bawan pada hari Rabu tanggal 24 Oktober 2018 pada pukul 08.15 WIB.
} 


\section{Nilai-nilai yang Terkandung dalam Pelaksanaan Tradisi Hewan Kurban}

Pertama, dapat menyempurnakan ibadah kurban. Tradisi menghiasi hewan kurban merupakan suatu yang sangat penting bagi masyarakat Kenagarian Bawan untuk mendapatkan kesempurnaan dalam beribadah kepada Allah Swt., karena suatu yang diberikan kepada Allah selain suci, bersih, niat yang ikhlas kepada Allah Swt. juga harus bagus. Untuk lebih sempurnanya ibadah kurban yang dilaksanakan, maka orang yang berkurban memperbagus hewan kurbannya. Salah satu tata cara masyarakat di Kenagarian Bawan untuk memperbagus hewan kurban, yaitu dengan cara menghiasi hewan yang hendak mereka jadikan hewan sembelihan. ${ }^{29}$

Kedua, menyenangkan hewan kurban. Ibadah kurban merupakan ibadah yang dilaksanakan sekali dalam setahun, yaitu bertepatan pada hari raya Idul Adha (10 Dzulhijjah) atau pada hari Tasyri' (11, 12, dan 13 Dzulhijjah). Ibadah kurban ini dilakukan untuk menunjukkan rasa syukur dan terima kasih seorang hamba kepada sang khaliq yang telah memberikan kelebihan rezeki dan kemampuan, sehingga ia bisa melaksanakan ibadah kurban. Selain itu, ibadah kurban yang dilaksanakan seorang hamba kepada sang khaliqnya juga menunjukkan sebagai ketaatan dan kepatuhan kepada Allah Swt., Agar ibadah kurban itu diterima oleh Allah Swt., maka orang yang berkurban menyenangkan terlebih dahulu hewannya, karena hewan itu telah bersedia mengorbankan nyawanya untuk disembahkan dan dijadikan kurban kepada Allah Swt.

Ketiga, dapat mengisi rohani bagi orang yang berkurban. Ibadah kurban bukan hanya saja bentuk kepatuhan dan ketaatan seorang hamba kepada sang khaliq. Namun, dengan melaksanakan ibadah kurban juga memberikan efek dan dampak kepada orang yang berkurban, yaitu dapat mengisi Rohaninya dan menghindari dirinya dari sifat kekikiran dan kesombongan.

\footnotetext{
${ }^{29}$ Ali Imran, wawancara dengan masyarakat Kenagarian Bawan sekaligus sebagai
} Ketua MUI Kecamatan Ampek Nagari pada tanggal 29 Agustus 2018 pada pukul 14.15 WIB. 
Keempat, dapat menyambung tali silaturrahmi antar masyarakat. Pelaksanaan tradisi menghiasi hewan kurban selain dapat menjaga tradisi yang telah dibawa oleh nenek moyang terdahulu juga dapat menyambungkan tali silaturrahmi antar masyarakat, seperti orang yang berkurban melaksanakan doa bersama dan menjamu masyarakat yang berada di sekitar orang yang berkurban termasuk alim ulama, imam khatik, tokoh masyarakat dan karib kerabatnya, sehingga hal itu terjalinlah hubungan silaturrahmi antar mereka. ${ }^{30}$

\section{PENUTUP}

Tradisi yang berkembang di tengah masyarakat yang berkaitan dengan ajaran Islam merupakan sebuah hiasan dan pelengkap dalam pelaksanaannya, sehingga jika dibawakan dalam ranah hukum Islam (bidang fiqh) tidak dapat ditarik kesimpulan haram atau tidaknya dalam melaksanakannya dan jika ada pemahaman yang berbeda serta menganggap tradisi itu merupakan sebuah ibadah ataupun ajaran, maka semua itu hanya argumen mereka secara pribadi. Namun, sebagai Akademisi tidak bisa langsung menjustifikasi, menyalahkan, bahkan bilang pelaksanaan tradisi itu sesat karena tidak ditemukan ajaran pada zaman Rasulullah Saw. Tetapi jadikanlah setiap tradisi yang berkembang di tengah masyarakat sebagai wawasan baru dalam ilmu pengetahuan bidang keagamaan maupun kajian terkhususnya dalam bidang studi living hadis.

\section{DAFTAR PUSTAKA}

Anas, M. 3 Tradisi Unik Perayaan Idul Qurban di Indonesia (2015).Kompas.com https://travel.kompas.com

Putra, Arif Eka. hasil wawancara dengan Staff Kesejahteraan Nagari Bawan pada tanggal 24 Agustus 2018

${ }^{30}$ Tuanku Rusli Labai Basa, wawancara dengan ulama Batang Dareh Jorong Lubuk Alung Kenagarian Bawan pada hari Rabu tanggal 24 Oktober 2018 pada pukul 08.15 WIB. 
Candra, Beny. wawancara dengan Guru Seni SMPIT Al Hijrah pada tanggal 08 September 2018 pada pukul 08.35 WIB

Damril. wawancara dengan Imam Masjid Nurul Jadid Padang Sibalungking Kenagarian Bawan, pada tanggal 23 Agustus 2018 pukul 11.18 WIB

Data Dokumentasi Kantor Wali Nagari Bawan Kecamatan Ampek Nagari Kabupaten Agam

Imran, Ali. wawancara dengan masyarakat Kenagarian Bawan sekaligus sebagai Ketua MUI Kecamatan Ampek Nagari pada tanggal 29 Agustus 2018 pada pukul 14.15 WIB

Imwarizal. wawancara dengan orang yang berkurban sekaligus Ketua Masjid Raya Pasar Bawan pada tanggal 22 Agustus 2018 pukul 10.37 WIB

Mansyur, M., dkk, Metodologi Penelitian Living Qur'an dan Hadis, Yogyakarta: Teras, 2007

Nguling. Tradisi Manten Sapi untuk Syiar Islam (2016).WartaBromo https://www.wartabromo.com

Endriani, Eva. wawancara dengan masyarakat Kenagarian Bawan, pada tanggal 18 November 2018 pukul 16. 26 WIB

Santoso, Heri Dwi. Apitan: Pelestarian Tradisi Agraris Lokal Masyarakat Jawa. Vol. 3, No. 2 (2013). doi: https://doi.org/10.26714/lensa.3.2.2013.11-19

Kaidir, Tuangku. Wawancara dengan ulama Kenagarian Bawan pada tanggal 02 Oktober 2018 pukul 05.45 WIB

Ali Basar, Tuangku Sidi. wawancara dengan ulama Kenagarian Bawan pada tanggal 29 Desember 2018 pukul 18.20 WIB

Panjang, Tuangku Imam. wawancara ulama di Kenagarian Bawan pada tanggal 27 Agustus 2018 pukul 14.45 WIB

Labai Basa, Tuanku Rusli. wawancara dengan ulama Batang Dareh Jorong Lubuk Alung Kenagarian Bawan pada hari Rabu tanggal 24 Oktober 2018 pada pukul 08.15 WIB 
Edriagus Saputra : Tradisi Menghiasi Hewan Kurban pada Masyarakat Kenagarian Bawan| 23

Zakirman, wawancara dengan tokoh masyarakat pada tanggal 27 Agustus 2018 pukul 16.30 WIB

Zuhri, Saifuddin dan Dewi, Subkhani Kusuma. Living Hadis (Praktik, Resepsi, Teks dan Transmisi), Yogyakarta: Q Media, 2018 
24| Fokus : Jurnal Kajian Keislaman dan Kemasyarakatan, Vol 4, No. 01, Mei 2019 